\title{
Urban Transformations and New Dynamics of Exclusions: A Mixed Method Study of Health and Well-Being in an Expanding City of India
}

\author{
Rakesh Chandra*\#, Saradiya Mukherjee" \\ Center for the Study of Regional Development, Jawaharlal Nehru University, New Delhi, India \\ Email: ${ }^{*}$ rakesh.12359@hotmail.com, ${ }^{*}$ rakesh.12359@gmail.com
}

Received 7 April 2015; accepted 23 June 2015; published 29 June 2015

Copyright (C) 2015 by authors and Scientific Research Publishing Inc.

This work is licensed under the Creative Commons Attribution International License (CC BY). http://creativecommons.org/licenses/by/4.0/

cC) (i) Open Access

\begin{abstract}
Indian society divided along the lines of Caste is a unique case for the study of exclusion. Caste based divisions and consequent exclusion has a significant impact on human well being in India. Even after significant restructuring of living spaces and social equations in the form of urbanisation, exclusion is implicit in Indian cities. It manifest in the form of social and spatial exclusion in Indian urban landscapes. In this study, we examine linkages between socio-spatial exclusion and health and well-being through certain pathways. Based in an urban village of Varanasi in India, this study is built on a mixed method. The population of the study area, although historically an integral part of city, were found to be marginalised and excluded socially and spatially in the whole process of urban transformations. Continued exclusion suffered by this urban village amid the city influenced well-being of its inhabitants negatively, particularly their patterns of health.
\end{abstract}

\section{Keywords}

Caste, Urbanisation, Exclusion, Well-Being, Health

\section{Introduction}

India is a land of contradictions. As a second most populous country of the world it is striving hard to come to terms with the socio-economic inequalities among its citizens. Indian society living with its past traditions and value is divided along the lines of Caste-a hierarchical organisation of society in different groups as suggested

${ }^{*}$ Corresponding author.

\#Authors are doctoral candidates at Center for the Study of Regional Development, Jawaharlal Nehru University, New Delhi, India.

How to cite this paper: Chandra, R., \& Mukherjee, S. (2015). Urban Transformations and New Dynamics of Exclusions: A Mixed Method Study of Health and Well-Being in an Expanding City of India. Current Urban Studies, 3, 135-146. 
in few ancient texts-rendering a number of groups of people inferior to others and depriving them of various social privileges as enjoyed by the others. Such arrangement of society made inequality and exclusion an inherent character of Indian society, wherein it continues to exist despite a significant restructuring of living spaces and social equations in the form of urbanisation. Cities, which are generally considered socially more open, accommodative, and liberal have a different story in Indian context and there are evidence of social exclusion and marginalisation in urban India (Banerjee et al., 2014; Thorat, 2005).

Social exclusion is a well-researched issue. However, most of the established theories in this context have been west-centric. The narrow or limited view of the concept of social exclusion was very evident when Power (2000) argued it to be almost entirely an urban problem or many other linked it with poverty (Room, 1995; UK Social Inclusion Unit, 1997; Blair, 1998). It is a fact that social exclusion was visibly more conspicuous in cities than in villages and poverty connected with it in a circular manner. However, these studies failed in presenting a theoretical understanding of social exclusion, which could be applied in different context to understand the issue. For instance, a person born in a low caste family in an Indian village was bound to face some sort of social exclusion notwithstanding his/her material achievements. To a great extent, De Hann (1997) had been successful in capturing it as a process embedded in the societal relations, and societal institutions through which individuals or groups are wholly or partially excluded from full participation in the society. Sen (2000) on the other hand conceptualized it in terms of "relational capability deprivation", which seemed to be theoretically more useful.

In India, "caste” has been a rigid social institution controlling societal relations. In caste based organization of society, members were divided in social groups (or castes) in which the civil, cultural, and economic rights of each individual caste were pre-determined by birth and made hereditary. Thus, there emerged a discriminatory assignment of civil, cultural, and economic rights depending on the place of a person or group in the caste hierarchy (Thorat, 2005). A person born in low caste family or a low caste group was deprived of certain capabilities in relation to a person or group belonging to an upper caste. Thus, caste-based exclusion has been embedded in social relations in India and its manifestation can be witnessed in terms of denial and discrimination in economic, civil, cultural, and political spheres (Dhesi \& Singh, 1989; Khan, 1995; Bhalla \& Lapeyere, 2002; Thorat, 2005). Additionally, what had been ignored or certainly less explored is the embedding of caste-based exclusion in spatial relations. Such relations were best expressed in morphology of an Indian village. In any Indian village, heterogeneous in terms of caste of its inhabitants, a distinct segregation among cluster of houses could be seen. Depending on caste of persons or groups and its place in caste hierarchy, their houses or house clusters were arranged in village. An upper caste person or group occupied core part of the village while those at the bottom of caste hierarchy or untouchables settled on the margins of village and intermediate caste groups filled up the space between two. The house cluster of low caste people had to maintain some spatial distance to other houses, however such distance between houses of upper castes and intermediate castes varied in different villages. Thus, the social distance between caste groups was also manifested in terms of spatial or geographical distance. Members of a lower caste group had not only limited spatial mobility in villages but they also suffered numerous restrictions on the use of common land and resources of the villages. Thus, caste-based exclusion was not only social but also spatial and, therefore, we conceptualized it as socio-spatial exclusion. Inequality inherent in social relations among different caste groups in India migrated with people from villages to cities and is quite visible in terms of marital relations, political formations and interest clashes. However impact of caste is less visible in the forms and patterns of settlements of cities, wherein any lower caste family can be neighbour of an upper caste family unlike in villages where there settlements are grouped and separated on the basis of caste identity. Thus while Indian cities can be said having caste inequality in social relations only, villages suffers intense socio-spatial divisions based on caste inequality.

With the process of urbanisation, the sprawling cities in India demanded more and more land and crept up to the thresholds of villages to engulf them. The encroaching city consumed the agricultural lands of the villages for its development process, whereas the village settlements remained. In most of the cases the upper caste settlements of the villages merged themselves well with the cities utilising their political reach and greater say in the policies of infrastructure development. However the settlements belonging to low caste population remained excluded socially as well as spatially and in most case ghettoed-up gradually. Such parts of villages, in the process of inordinate urban sprawl not only remained villages_often called urban villages — but turned in to dumping yard for aesthetically and environmentally undesirable setups and low cost refuge for people required only to serve the city, mainly labourers. Urban villages as those exist in large number in china ${ }^{1}$ and in Indian

${ }^{1}$ Urban villages were extensively studied in china whereas it was hard to find a single published study in Indian context. This is because we referred to china to understand the concept. 
cities, too, were the result of ill-conceived plans of governments for proliferating cities. These urban villages encircled by cities were characterized by low rent housing for immigrants and which also replaced the agriculture as main source of income for the villagers (Zheng et al., 2009). But the case we are studying was similar to Chinese urban village in the sense that it was surrounded by city and its dwellers cherished old age rural value, whereas it differed in terms of socio-spatial exclusion suffered by its inhabitants. However the cause of such sufferings, i.e. caste discrimination lies deep in the social history of India and goes unabated even in $21^{\text {st }}$ century despite the "liberating" urbanisation in full bloom.

The study area known as Nagwa Harizan Malin Basti $\left(\right.$ slum$\left.^{2}\right)$ was located in the ancient city of Varanasi, often referred as "the city of temples", in the state of Uttar Pradesh in India. It was spread in south of the city surrounded by market place, gated communities and residential buildings. Gradual and unbridled sprawl of the city took the study area in its fold as it did with many other villages and their hinterland. Since inhabitants of Nagwa Basti belonged to Scheduled Castes $(S C)^{3}$, which historically was a group of outcastes ${ }^{4}$, it remained unassimilated in the city socially as well as spatially. Some historical source revealed that inhabitants of the village were relocated in the south of city from the northern part by Kashi Naresh (The King of Varanasi). It was done by considering the fact that wind direction was less frequent from South to North and thus inhabitants of city core located in the north, which mainly consisted of upper caste people and saints, could be saved from purity pollution $^{5}$ !

The inhabitants of Basti, as will be seen in the analysis further in this paper, had much of rurality left with them in terms of social relations, psychological disposition and physical assets. This urban village was different from that of many studied in China and West End of Gans (Gans, 1967) in terms of of exclusion and deprivation suffered by its inhabitants. Being situated in the secular cities of China, the urban villages-many of that kind also exist in and around Delhi-became major centre for low rent housing for immigrants working in the city. Thus, villagers who lost their agricultural land in the sprawl of city now had house rent as their main source of income. But, the story of the Nagwa Basti was different-homogenously occupied by SC population, which were historically discriminated as untouchables by higher castes with notion of purity pollution, this place lost its potential to emerge as a source of low rent housing. Contrary to this rent accommodation was a characteristic feature of the housing in surrounding areas since long back. Thus, social injustice seemingly controlled space production and spatial justice in the case of Nagwa Basti. A place stigmatized by the habitation of low caste people remained isolated, whereas its surroundings were assimilated in the city. This process of socio-spatial exclusion had multidimensional impact on the lives of its inhabitants, which obviously included their health status as well.

\section{Health and Place}

There is a significant body of literature suggesting links between health and place. Deprivation, marginalization or exclusion having socio-spatial dimensions leads to negative health scenario through various pathways (Wilkinson, 1996; Yen \& Syme, 1999; Pickett \& Pearl, 2001; Kawachi \& Kennedy, 2006; Poortinga et al., 2007; Feldman et al., 2009; Reuttar et al., 2009). The prominence of the neighborhood effect and individual socioeconomic status as a determinant of health outcome is also debated (Anderson et al., 1997; Robert, 1998; Bosma et al., 2001; Browning \& Cagney, 2003; Heady et al., 2006; Fone \& Dunstan, 2006; Kelly et al., 2007). However, it is a well established fact that marginalized and excluded neighbourhood have certain effects on the health of individuals via material, psychosocial and behavioural pathways (Stafford \& Marmot, 2003; Poortinga et al., 2007; Feldman et al., 2008). In the case of Nagwa Basti, the area or neighbourhood effect seemingly neutralizes the differences (indeed a very little among the residents) at the individual level. The Basti was homogenously inhabited by Scheduled Caste population and characterized by households' deplorable living condition and surroundings. Invariability of the compositional factors and poor health status of residents as general phenomena,

\footnotetext{
${ }^{2}$ In the government records the place, historically a village, was recorded as slums. Going by definition it was indeed a slum physically and materially but socially it retained old village character. It was because of exclusionary process of urbanisation this place turned out to be what it was. Therefore we refrained from using term "slum" for the place and mentioned it as Nagwa Basti (English translation-Nagwa settlement) or Basti (settlement) here as well as elsewhere in the whole text. It was also the common name used by locals to refer the place.

${ }^{3}$ Schedule Caste is a group of people recognized by Constitution of India as socially and economically disadvantaged. Constitution of India enlisted a number of caste groups under this category for their socio-economic welfare.

${ }^{4}$ Outcastes were those groups of people in Indian society which found no place or the lowest in caste hierarchy and were excluded from society on several counts and considered untouchables.

${ }^{5}$ Fear of upper caste people of being impure by the contact of low caste people.
} 
allow us to relate specific health conditions of the Basti to socio-spatial contextuality, which of-course was punctuated with marginalization and exclusion. There are a number of pathways by which socio-spatial contextuality marked with deprivation and exclusion might influence the health pattern of a place. A number of studies recognize such different pathways i.e. physical environment and material condition (Cohen et al., 2003; Crawford et al., 2008; Frumkin, 2003; Gatrell et al., 2000; Leyden, 2003; Ross \& Mirowsky, 2001; Srinivasan et al., 2003); psycho-social processes (Geis \& Ross, 1998; Stafford \& Marmot, 2003; Ziersch et al., 2005); cultural and behavioral factors (Duncan et al., 1999; Bosma et al., 2001; Frohlich et al., 2002; Lee \& Cubbin, 2002; Reijneveld, 2002); and accessibility of quality healthcare services (Yen \& Kalpan, 1999; Furler et al., 2002). It is a tough job to segregate the compositional and contextual effects while analyzing the association between socio-spatial exclusions and health. However, this might not be required in this case as poor health status was a general phenomenon in the Basti with a small variability of compositional factors. A major purpose of this study is to analyze a few earlier established links or pathways, as mentioned above, that mediate the association between exclusions and poor health. A new addition in our work however will be an effort to bring in the spatial dimension of exclusion into the picture. This study focuses on the caste baste social and spatial segregation of an area and records its impact on the physical condition, perception and behavioural dimensions of people of the area that possibly mediates socio spatial exclusion and its fall out in terms of poor health. The problems related to health of the population of study area are also accounted separately.

\section{Data and Methodology}

The data for this paper was collected during January and February in the year 2009. Ethical clearance for the research was provided by Department of Geography at Banaras Hindu University. The participants in the study were informed of the intention of author and purpose of research. They participated in the study voluntarily and were assured of confidentiality and anonymity regarding information collected.

\subsection{Participants}

The data collected for this study included only adult men of the Nagwa Basti, one from each household. The reason behind exclusion of female is that the researcher, being a male, found himself to be unable to generate adequate responses from them ${ }^{6}$. Almost all the households were covered and a total 150 men were contacted in the different phases of data collection and many of them were part of both stages.

Respondents belonged to different age groups. A large portion of them was in the range of 20 to 40 years (around 60 percent) whereas the youngest was 18 years old and eldest 67 years old. Around 40 percent of the study population had no schooling while one-fourth of the total was dropouts and only 5 percent could complete graduation. Most of them were employed as manual and non-skilled labourers and only 3 percent had permanent government jobs. A total of 66 percent of study population had a monthly income within range of $\$ 18$ to $\$ 91$, whereas 15 percent were below $\$ 18$ and 10 percent had no source of income. All the respondents belonged to the Basti and were the natives of the place. Individuals in the study area responded well and they were more than willing to talk.

\subsection{Methodology}

A mixed method approach was adopted in this study. A mixed method study integrates both quantitative and qualitative research methods. There are several strategies of data collection and analysis under mixed method design (Tashakkori \& Teddlie, 1998; Creswell, 2003). In the present study, we used "sequential exploratory strategy", which comprised two phases. First phase of the study included qualitative data collection and analysis, which provided a base for the buildup of second phase. Depending on how we connect the two phases and relative emphasis of the two, Creswell and Clarke (2007) specified two variant of this design: the Instrument Development Model and the Taxonomy Development Model. In our study, we were more aligned with Taxonomy Development Model in which researcher identifies categories and relationships in the qualitative phase and supports them with the quantitative observations of second phase (Tashakkori \& Teddlie, 1998; Creswell \& Clarke, 2007). We explored the phenomena of socio-spatial exclusion and its probable manifestations on health and attempted to recognize links between two through qualitative methods. In the second phase which developed on findings of the first phase, we tried to provide quantitative underpinning to the observation of the first

\footnotetext{
${ }^{6}$ In Indian village society woman interaction with an unfamiliar man is socially unaccepted, particularly in North India.
} 
phase through an instrument. Since, we began with a priori that socio-spatial exclusion affect general level of health, this design provided us the scope to unravel exclusion and its ramifications in first part and substantiate it with the quantitative observation of health status in the second.

Qualitative data collection process entailed a walk through observation; two key informant interviews, thirty five in-depth interviews and three focus group discussions, each constituting five to seven members. The key informant interviewees were a local medical practitioner and a social worker. The members of focus group discussions were representative of different age-group, occupation, income and level of education. A survey using scheduled questionnaire was conducted to collect quantitative data on similar issues that had already been explored during qualitative data collection. Lastly, the integration of the data analyses of two phases provided a picture which was more reliable and comprehensible than that drawn in either. It is worth mentioning that out of the two, qualitative data and analysis is emphasized in any case, however the coded data based on survey aided in cross checking the information and assisted in the build-up and extension of the findings.

\section{Findings}

\subsection{Health Problems}

Most of the inhabitants of the Basti perceived them to be free of any health problem. Although they did not forthrightly accept that they had any health problems as such, probing little deep revealed not only their current health crisis but also sufferings of the past. The location of the Basti always made it prone to infectious diseases like, cholera, small pox and diarrhoea. Outbreaks of these were common in the past and would not left any houses of Basti. However, a few more like tuberculosis, malaria, jaundice and different kinds of fever have recently surfaced although the outbreaks have been less frequent and severe. One of the obstacles we faced during interviews was that the participants self-rated their health as "better" invariably and were ignorant about what a good health constitutes. A sense of self-appreciation prevailed among respondents, which led them to think that they were different from those living outside their Basti, and were more resistant to any kind of diseases than their counterparts living in better urban conditions outside the Basti. They were not ready to accept that they could also have any disease; and underrated common ailments no matter it were regular or frequent. Moreover, most of the respondents who ever suffered or were suffering any kind of health problems lacked complete diagnoses due to several reasons including lack of interest in life, ignorance, inaccessible government health system and economic problems.

Tuberculosis (TB) was prevalent in the Basti and a total of thirteen respondents accepted that they suffered with disease, out of which four were still undergoing treatments. Prevalence of abdominal pain and problem of Gastroenteritis were perceived to be very common and normal by the respondents. Around fifty percent of the respondents complained about it and thought it to be related with their food habits. However, a local medical practitioner from the Basti informed us in the interview that the quality of water was responsible for the problems of abdominal pain and gastric. Around twenty percent of the respondents complained to have some kind of respiratory problem. Some of them were infected so badly that they could not talk comfortably. They could not identify the causes for the problem because most of them never went through a complete diagnosis from a qualified health professional. Moreover, most of the respondents showed certain symptoms of depression though they did not accept it as any health problem. Respondent perceived anxiety and depression to be normal, universal and incurable.

\subsection{Physical and Material Well-Being}

The socio-economic and material condition of Basti people had been deplorable historically, although they think it was improved but an observer might exclaim that if the present exhibited improved condition (not liveable indeed), how the past would had been. It was evident by their own accounts that they had a past marked with exclusion, deprivation and exploitation. They lived in dilapidated mud walled thatched houses which could not resist heavy rainfall and roofs and floors would come down in rainy seasons every year. They worked in the field of landlords for a nominal kind and never had enough to eat. They did not have any source of water of their own and were not allowed to use those lying in the areas of upper castes. They therefore drank water from River Ganga $^{7}$ which, for a large part of the year, remained turbid. Many times they had to cook dead animals because ${ }^{7}$ Ganga is a river in north India originating from Himalaya. 
of unavailability of grain. In the name of health facility, they had services of only some traditional healers locally known as $\mathrm{Hakim}^{8}$ and those too, would never touch their pulse as they were untouchables. Most of the population used to take Kharbariya Dawa .

Things have changed in last twenty years, as they described it, but still exclusion and deprivation remained. Now, they were paid for their work (for years they worked for petty kinds or as bonded labour), no matter how disgraceful it was perceived by other; they had government water taps, no matter if it supplied impure water; alleys, no matter how narrow, could be used throughout the year as they were now covered with stone flakes; the walls of their houses were now made up of brick and mortar although thatched roofs were also found in some houses; they had access to doctor although in private clinic but a secular one. There were only a couple of issues remained to be solved and the place would be perfect to live in, they told!

There were four main passages to enter in the Basti, which looked like an island surrounded by well built houses and affluent society. The streets of the Basti were narrow and covered with stone-flakes and most of them were so narrow that even two motorcycles could not pass simultaneously. Roads were paralleled by open and choked drains and a number of hand pumps and public taps fixed along with them. Waste-dumping sites with gathering of stray animals were common scene. The houses were congested and arching over alleys they prevented sunlight from touching the ground, making it dark and damp. Although most of the houses were of mortar and brick, many of them still bore the traces of village with mud walls and thatches. The houses were low height and rooms were generally undersized with and without ventilators. Cooking on earthen stoves in open spaces was common sight in this Basti. To the north of Basti, people residing along a drain had constructed open toilets over it. This sewage drain made the air stinky and it was hard to stay in adjacent houses for a while. The wall sides and corners of the Basti smelt of urine and children could be seen defecating and relieving over the drains. Only a few houses had functional private toilets of their own, while most of the households depended on the two Sulabh ${ }^{10}$ toilets. Men having bath under public taps was very common scene. There was only one private health clinic serving entire Basti and, that too, was located outside the Basti.

As for economic status of the people living in the society, we found that almost all of them were very poor. A few of them had cattle and poultry, whereas none of them owned land other than that occupied by their houses. Although this area of the city received immigrants in various forms and renting the house was a major source of income for many, renting business in the Basti was absent, except a few households where migrant rickshaw pullers and labourers lived as tenants.

\subsection{Perception}

Most of Basti residents perceived various addictions, like alcoholism, chewing Massala ${ }^{11}$ (not Pan/ betel quid ${ }^{12}$ ) and other substance abuse as major causes for their health problems. Only a few of them considered that the Basti environment had something to do with their poor health conditions. Among the factors that interviewees and participants of group discussions perceived to be responsible for their health problems, food and dietary habits were most common. The logic behind such thinking, as came out from focused group discussions, was that everything what they eat was contaminated with fertilizer and other agro-chemicals used in agriculture. The argument given in the support of this idea was that their forefathers used to be healthier than them, because in their time everything used to be more natural and unadulterated including food. Moreover, habits and practices of daily life were perceived to be at second place as a cause for their poor health. The fact behind this idea was high prevalence of alcoholism in the Basti as more than seventy percent of respondents were found to be alcoholic. Boozing was becoming a culture in Basti, and not a single day was dry day as one interviewee emphasized "Liquor is the problem of all, every household has one or two alcoholic and it is the root cause of every illness". Although it was considered a bad habit and many of them wished to quit, but expressed their helplessness before peer-pressure and the nature of profession. Physical environment and sanitation issues of the Basti came at third place as a factor affecting their health. According to respondents, the environment of Basti was "perfect" only if ${ }^{8}$ Hakim is a term in local language used for quack (local traditional healers). However, the term "quack" may not be suitable for many traditional healers (Hakims) who had proper training and relevant degrees in Ayurvedic or Unani (Greek) medicine system.

${ }^{9}$ Kharbariya Dawa is a term in local dialect used for the homemade medicines prepared with locally available ingredients.

${ }^{10}$ Sulabh is an international social service organization engaged in establishing public toilets in India. The toilets established by organization in country are commonly called Sulabh.

${ }^{11}$ A preparation, containing Betel nuts, Catechu, Tobacco, Lime and other ingredients including some chemicals.

${ }^{12}$ Pan or Beetle quid is more or less similar preparation like Massala but it contains beetle leaves. It is culturally accepted in Varanasi. 
Assi Nala (drain) could be covered. A sense of comparison and relativity controlled the ideas of respondents. They had seen, as accounted by few old age respondents, much filth and insanitation in the past that even little improvements in the Basti made them feel good and healthy. However, the heaps of garbage, oozing open drains, open urination, stinking Assi Nala, swarm of houseflies and the buzz of mosquitoes were still part of the Basti landscape. Respondents believed that the drinking water in their Basti was as pure as it was in any other well off locality. Only a few respondents considered it to have negative impact on their health. It is worth mentioning here that the accessibility to sources of water was now better compared to days of past, when they had to struggle for drinking water. Now they had water for their daily needs from public taps and hand-pumps located within their Basti. Thus their existed a gap between the perception and realities of Basti people about their place and it was created by the fact that there was a bit of improvement in the conditions although it was not conducive to good health from any standard.

The interview with a local health practitioner revealed that the prevalence of water borne diseases was very high. He divulged that patients suffering from such diseases were given medicine on the basis of primary symptoms and the process of formal diagnosis was avoided because patients were too poor to afford the cost of medical tests. He feared that a prescription listing several check-ups and tests might bring him tag of an "expensive doctor". There were several sources of contamination of the water that was being used in Basti. They included damaged water supply pipes, infiltration of polluted water of Assi Nala to deep water table and inappropriate water storage in the houses. Toilet is one of essential basic amenities in an urban environment but for Basti people it was an undesired necessity. The Basti had two Sulabh toilets and few inhabitants had private toilet in their houses under a government scheme, but they perceived these newly constructed closed toilets negatively and lamented for those old "good days" when they used to go on the bank of river Ganga to attend nature's call in an open space. It is an established fact that environment contaminated by human or other faeces helps spread many infectious disease including cholera, typhoid, hepatitis, and polio. However, only twenty percent of the respondents perceived that defecation in an open space could be harmful. Other 53 percent found that it had no impact on their health whereas, another twenty seven percent perceived it to be healthy. An agreed logic behind such idea was that defecating on river bank in the morning and evening gave them fresh air, which was healthier than using closed, suffocating private or public toilets.

We also probed on the issues related to vasectomy and contraception. It was found that more than seventy percent respondents perceived it to be harmful if taken. The harm, according to them, was physical weakness and loss of social respect. Only twenty five percent respondents accepted it to be secure and they too changed their mind when question "who should go for sterilization — male or female?" was asked. A great majority of respondents emphasized that women must go for sterilization. They argued that men were the bread-winners for the family and if they got sterilized, they would become weak and not be able to work. Some of them argued that they have witnessed cases wherein even sterilized men became father of a child later on. One argument against vasectomy was that it might render a man impotent and then his wife would go to the others to fulfil her sexual desires. The respondents were divided in their views on the use of family planning methods/contraceptives. Some of them supported the idea while others rejected the use of family planning. A respondent expressed, "if a man was firm to control numbers of his children there was no need of any kind of contraceptives". He further discarded the utility of these methods by saying that, "many fellows became father even after having an operation (Vasectomy) done". However, there were a few who perceived condom and other means of contraception to be necessary in modern times for many reasons.

Perception of respondents about their health conditions was explored by offering them a comparison of their health problems to that of "well off" populace of surrounding communities. The question "who suffered more health problem" generated a mixed response. Some of them emphasised that poor faced less health problem as their unfavorable living conditions make their bodies stronger, adaptive and immune to various sorts of illness. On the other hand, some opined that rich people had more money and facilities to maintain better health. However, majority of discussants were of opinion that "rich people who lived in surrounding colonies were having more health problems". Almost all the participants of a group agreed when a member asserted, "those rich people in surrounding colonies, who live in much comfort and ease suffer more serious diseases than we poor have. The more money they have, the more they are worried". Another participant added, "We are even healthier and happier than rich people". A total of forty five percent respondents accepted that the poor face less health problems while fifty percent was of opinion that it is the rich who face more health problems. They endorsed their views by arguments like- the poor have strong immune system, resisting power, adaptation capacity in any 
physical conditions and sound character whereas the rich has enough power and money to avail health facility, good food, luxury etc. Further on the question of doctor's role in the health of the community, about fifty five percent respondents opined that they were only concerned to earn money. Many of the respondents perceived them as "blood suckers", who only cared for their fees and commission. These opinions of respondents, as they told, were based on their past experiences with doctors in public and private hospitals.

\subsection{Behavioural Dimensions}

This part of the study deals with the analysis of data collected on the practices and ways of day to day life of respondents that might have an impact on their health. The first practice in this order is the treatment seeking behaviour of respondents. It was found that around fifty percent of respondents approached nearby medical store or grocery shop to get medicine at the event of illness. The main reason behind such action was economical and prevailing mistrust among respondents toward medical practitioners. Many argued that it was worthless visiting a doctor and getting lengthy prescriptions when a tablet from medical store could work wonders. They doubted that doctors prescribed expensive medicine and diagnostic tests to get commission from medical stores and pathology labs. Moreover, there were around twenty percent respondents who expressed that they waited for the problem to be cured by itself. Although, main cause behind such attitude was financial constraints, some opined that medicines cured a disease but were harmful as well; therefore, it was better to avoid heavy dosages of pills. Probing on "what do they do when they have a health problem?" revealed different courses of action taken by respondents at the event of illness. Only thirteen percent respondents immediately visited to doctor when they faced a health problem while another fourteen percent took a whole day to decide to visit to doctor. A large majority of respondent waited for at least two or more days before they visited a doctor. Such responses supported the findings from previous question, which shown delay in making a prompt visit to doctor because of economic problems and lack of trust toward doctors. Some respondents also accepted that they went to a faith healer and used Kharbariya Dawa (homemade medicine) at the event of illness. Many of them lamented that genuine faith healers were hard to find and materials needed to prepare homemade mixtures were scarce, costly and sometimes unavailable. Nevertheless, they practiced many traditional ways (taking curd and banana) to cure jaundice and dysentery. Many of them considered it to be unusual to visit doctors for every health problem. One elderly expressed it as, "now time has changed people immediately rush to the doctor, "even" at the arrival of Mata Raani ${ }^{13,}$.

Perception of respondents on different ways of attending nature's call has been examined earlier. A significant number of respondents were in favour of using open space as toilet, which according to them was healthier in comparison to private or public toilets (Sulabh). Under this section a questions, "which type of toilet in use" was asked and in response 70 percent told that they were using some kind of built toilet, rest of them accepted that they still defecate in open spaces. In fact many of them lamented that they were forced to use toilet built in home because the river bank, the only place to attend nature's call in past, was occupied by various constructions.

Many medical experts consider addiction as a "chronic relapsing disease" wherein addict spends time and money to get various legal and illegal substances. In this regard, respondents were asked questions in the both phases of the study. Only around nine percent of respondents were found to be non addict, wherein 10 percent were smokers and other nine percent were taking other narcotics and rest were having other sort of addictions. Taking Pan and Massala regularly was not considered to be an addiction. Majority of respondents had a habit of chewing these substances and they argued it to be an essential habit in order to avoid other addictions! Many of them were found defending this addiction in the group discussion. For instance, a man uttered, "The addiction of one or two things is the need of a man". Alcohol was most common addiction after Pan and Massala and was found prevalent in both sexes and all age groups. So much so, Basti women would not go to their neighbours' home to sing in nuptial ceremonies if host was not supposed to offer them liquor. About three fourths of the respondents conceded to drink alcohol regularly. They defended this practice arguing that economic stress, peer pressure, depression, and nature of profession makes it necessary to have alcohol. Although elderly in the community seemed to have some understanding of its negative impact on health, however they found themselves unable to check this tendency among younger ones as nobody took them seriously. They considered physical exercise good for health but it was not a part of their daily life. One of them argued "we do so much of hard

\footnotetext{
${ }^{13}$ In basti, as in many villages of india, pox is taken as fury of a goddess called Mata Rani.
} 
physical work, so there is no need of any exercise".

Dietary habits of a person have direct impact on the physical as well as mental health of a person. Intentionally or unintentionally, this fact was ignored and diet was taken for granted by the respondents in the community. Most of them considered food to be affecting their health but that was, according to them, because of contaminated food and shortage of food to full belly and not because it was not nutritious. None of them mentioned about healthy diet which could support a good health. They eat meat and fish to mark a celebration; green vegetables because they were cheaper. One respondent disclosed, "I don't like green vegetables much but since it is cheaper than others so I eat it more regularly". They told that they had milk as it came mixed with tea; they eat fruit because they were fruit seller but they don't eat any of them as it could be good for their health.

\section{Discussion}

The Nagwa Basti community suffered socio-spatial exclusion historically and has been prone to various short of health crises. They have been distanced from the mainstream world as an outcaste village and deprived of community resources in the past, as they survived to suffer. Gradually, this place was caught in the urban drift that however could not assimilate it in the grand old city of Varanasi. Instead, it emerged as an urban village with a repulsive tag of "slum" and thus was denied of its share in flourishing market of rent housing. How did the caste of the inhabitants of a place conspire to alienate them in the process of development might be a different issue that needs an in-depth sociological inquiry. However, it could be argued that it was certainly a major factor in the social exclusion of the community, which ultimately caused and perpetuated spatial exclusion and injustice. This in turn influenced their health status via distorted pathways i.e. material condition, perception and practices.

A relative improvement over the horrendous past, characterized by extremely poor living conditions and health, in the lives of inhabitants of place cannot be denied. This fact has possibly modified their perception about surrounding realities and also reflects in their ideas and thoughts. They perceived their Basti environment to be well and good and will become perfect if some other minor improvements could be put in place and that existing health problems were very insignificant and unrelated to it. In terms of health and disease, too, gloomy visuals of the past, when almost every house would face causalities when cholera attacks struck, forced them to perceive their present much brighter as at least deaths because of diseases almost stopped. On the other hand, others frequently occurring diseases, such as jaundice, malaria and dysentery, were taken to be normal as they could be cured by little effort. There was some kind of relative satisfaction among them as far as their present situation was concerned. Now they were having water from taps and hand-pumps instead of river Ganga that was supposed to be pure and clean. Most of them did not see any role of their place and living conditions in their poor health and considered the health of themselves and other people in Basti rather normal and in sync with that of their relatively affluent neighbourhood.

The world beyond Basti changed more rapidly which brought up some social relaxations in terms of caste based discrimination and improvement in physical environment and material conditions, nonetheless these changes were not enough to prevent them from lagging behind. By and large, the whole community was ambivalent in its reflections on practices related to their health and general well being. They appreciated the little improvement caused by spill over of neighbourhood urbanisation; at the same time they also cherished elements of age old rurality and lament for their extinction. Similar to their past, in present world also they have only a few reasons to cheer on whereas a larger part of the picture was still dismal and thus the story of eternal exclusion and deprivation goes on. There is a significant body of literature that establishes connections between exclusion and deprivation and poor health. As discussed in the introductory part of the study deprivation and exclusion not only put the sufferers in direct relative disadvantage but also affect their health through a number of pathways. In this study, we did not attempt to establish linkages between exclusion and poor health instead we emphasized on certain pathways, i.e. physical environment and material condition, psychological factors and behavioural dimensions, which might affect the health of inhabitants. It is worthwhile to note that these pathways in themselves were morphed by socio-spatial exclusion and thus resulting into a poor health scenario in Basti.

In the analysis certain important points emerged that needs to be summarized before we conclude:

a) Life in Basti was a curious mix of age old cherished rurality and imposed urban way of life.

b) Inhabitants of Basti always remained excluded, both spatially and socially, earlier from the mainstream village and now from urban surroundings, which deprived them of economic advantages, facilities, modern in- 
novations and ideas related to urbanisation.

c) Although, the living conditions in the comparison of past have improved, the place, still, in no ways seems to be supporting a healthy life.

d) The socio-spatial exclusion and related deprivation not only controlled their ideas pertaining to healthy life but also overall health outcomes.

e) A low level of health of men was observed who had several misconceptions about health with numerous unhealthy practices and low level of awareness.

f) A notion of self-rated better health prevailed among the male inhabitants of the Basti, probably because of thinking of being different from the residents of relatively wealthy and better urban neighbourhoods.

These findings are more significant in present scenario when the urban sprawl in Varanasi-as in many other cities of India-is at its peak engulfing more and more villages and leaving its natives confused and hapless in the urban drift. India is a home of around 830 million rural populations and a large part of that is living in caste based villages. People in these villages are prone to exclusion and deprivation although its nature might vary place to place depending on their socio-economic and spatial capability to cope up the situation. It was nothing but the agony of caste based socio-saptial exclusion that reflected in the words of Ambedkar when he said “What is a village but a sink of localism, a den of ignorance, narrow mindedness and communalism?” Ambedkar was one of the most ardent supporters of urbanisation in India as he thought it to be a liberating force. But whether the current pattern of urbanisation in India is making qualitative changes in lives of all is a question worth asking. In current process of urbanisation in India, a significant size of population-like those living in Nagwa Basti-remains deprived of advantages of urban “developments” but have to bear the brunt of negativity of urbanisation particularly in the context of health. So, how this situation can be tackled? One answer is policy making based on "social inclusion framework" (Galabuzi, 2002) which demands institutional efforts for the protection of social rights of individuals. However, in India, where villages are not of secular origin and where social relation (mainly based on the caste) controlled their spatial pattern, one size fits all approach would not work. Institutions have to understand place specific realities to integrate and include villages socially and spatially in planned and unplanned growing cities. This might be one of the most appropriate ways to save the growing urban villagers from exclusion and deprivation and its fallouts on the various aspect of their life including health.

\section{References}

Anderson, R. T., Sorlie, P., Backlund, E., Johnson, N., \& Kaplan, G. A. (1997). Mortality Effects of Community Socioeconomic Status. Epidemiology, 8, 42-47. http://www.jstor.org/stable/3702421

Banerjee, A., Mishra, V. K., Rizvi, F., \& Ahmad, M. (2004). Discrimination in the Urban Rental Housing Market: A Spatial Analysis of the Delhi Region. Journal of Social Inclusion Studies, 1, 135-147.

Bhalla, A., \& Lapeyre, F. (2002). Social Exclusion: Towards an Analytical and Operational Framework. Development and Change, 28, 413-433. http://dx.doi.org/10.1111/1467-7660.00049

Bosma, H., Dike van de Mheen, H., Borsboom, G. J., \& Mackenbach, J. P. (2001). Neighborhood Socioeconomic Status and All-Cause Mortality. American Journal of Epidemiology, 153, 363-371. http://dx.doi.org/10.1093/aje/153.4.363

Browning, C. R., \& Cagney, K. A. (2003). Moving beyond Poverty: Neighborhood Structure, Social Processes, and Health. Journal of Health and Social Behavior, 44, 552-571. http://www.jstor.org/stable/1519799 http://dx.doi.org/10.2307/1519799

Cohen, D. A., Farley, T. A., \& Mason, K. (2003). Why Is Poverty Unhealthy? Social and Physical Mediators. Social Science \& Medicine, 57, 1631-1641. http://dx.doi.org/10.1016/S0277-9536(03)00015-7

Crawford, D., Timperio, A., Giles-Corti, B., Ball, K., Hume, C., Roberts, R., \& Salmon, J. (2008). Do Features of Public Open Spaces Vary According to Neighbourhood Socio-Economic Status? Health \& Place, 14, 889-893.

http://dx.doi.org/10.1016/j.healthplace.2007.11.002

Creswell, J. W., \& Clark, V. L. P. (2007). Designing and Conducting Mixed Methods Research. Thousand Oaks, CA: Sage Publications.

De Haan, A. (1997). Poverty and Social Exclusion: A Comparison of Debates on Deprivation. PRUS/IDS Workshop, 28-29.

Dhesi, A. S., \& Singh, H. (1989). Education, Labour Market Distortions and Relative Earnings of Different Religion-Caste Categories in India. Canadian Journal of Development Studies, $X$, 75-89.

Duncan, C., Jones, K., \& Moon, G. (1999). Smoking and Deprivation: Are There Neighbourhood Effects? Social Science \& 
Medicine, 48, 497-505. http://dx.doi.org/10.1016/S0277-9536(98)00360-8

Feldman, P., Warr, D., Tacticos, T., \& Kelaher, M. (2009). People, Places and Policies-Trying to Account for Health Inequalities in Impoverished Neighbourhoods. Australian and New Zealand Journal of Public Health, 33, 17-24. http://dx.doi.org/10.1111/j.1753-6405.2009.00333.x

Fone, D. L., \& Dunstan, F. (2006). Mental Health, Places and People: A Multilevel Analysis of Economic Inactivity and Social Deprivation. Health and Place, 12, 332-344. http://cat.inist.fr/?aModele=afficheN\&cpsidt=17638132 http://dx.doi.org/10.1016/j.healthplace.2005.02.002

Frohlich, K. L., Potvin, L., Chabot, P., \& Corin, E. (2002). A Theoretical and Empirical Analysis of Context: Neighbourhoods, Smoking and Youth. Social Science \& Medicine, 54, 1401-1417. http://dx.doi.org/10.1016/S0277-9536(01)00122-8

Frumkin, H. (2003). Healthy Places: Exploring the Evidence. American Journal of Public Health, 93, 1451-1456. http://dx.doi.org/10.2105/AJPH.93.9.1451

Furler, J. S., Harris, E., Chondros, P., Davies, P. P., Harris, M. F., \& Young, D. Y. (2002). The Inverse Care Law Revisited: Impact of Disadvantaged Location on Accessing Longer GP Consultation Times. Medical Journal of Australia, $177,80-83$. https://www.mja.com.au/journal/2002/177/2/inverse-care-law-revisited-impact-disadvantaged-location-accessing-longer-g D

Gans, H. J. (1967). The Urban Villagers: Group and Class in the Life of Italian-Americans. New York: Free Press.

Gatrell, A., Bostock, L., Popay, J., Williams, G., Shuhtahmasebi, S. (2000). Understanding Health Inequalities: Locating People in Geographical and Social Spaces. In A. Gatrell, L. Bostock, J. Popay, G. Williams, \& S. Shuhtahmasebi (Eds.), Understanding Health Inequalities (pp. 156-169). Buckingham: Open University Press. http://eprints.lancs.ac.uk/id/eprint/14178

Geis, K. J., \& Ross, C. E. (1998). A New Look at Urban Alienation: The Effect of Neighborhood Disorder on Perceived Powerlessness. Social Psychology Quarterly, 61, 232-246. http://www.jstor.org/stable/2787110 http://dx.doi.org/10.2307/2787110

Kawachi, I. (2006). The Health Of Nations: Why Inequality Is Harmful To Your Health. New York: The New Press.

Kelly, M., Morgan, A., Bonnefoy, J., Butt, J., \& Bergman, V. (2007). The Social Determinants of Health: Developing an Evidence Base for Political Action. WHO Final Report to the Commission, 677-690.

Khan, M. A. (1995). Human Rights and the Dalits. Delhi: Uppal Publishing House.

Lee, R. E., \& Cubbin, C. (2002). Neighborhood Context and Youth Cardiovascular Health Behaviors. American Journal of Public Health, 92, 428-436. http://dx.doi.org/10.2105/AJPH.92.3.428

Leyden, K. (2003). Social Capital and Built Environment: The Importance of Walkable Neighborhoods. American Journal of Public Health, 92, 1546-1551. http://dx.doi.org/10.2105/AJPH.93.9.1546

Pickett, K. E., \& Pearl, M. (2001). Multilevel Analyses of Neighbourhood Socioeconomic Context and Health Outcomes: A Critical Review. Journal of Epidemiology and Community Health, 55, 111-122. http://dx.doi.org/10.1136/jech.55.2.111

Poortinga, W., Dunstan, F. D., \& Fone, D. L. (2007). Perceptions of the Neighbourhood Environment and Self Rated Health: A Multilevel Analysis of the Caerphilly Health and Social Needs Study. BMC Public Health, 7, 285. http://dx.doi.org/10.1186/1471-2458-7-285

Power, A. (2000). Poor Areas and Social Exclusion. Social Exclusion and the Future of Cities. London: Centre for Analysis of Social Exclusion, London School of Economics.

Reijneveld, S. A. (2002). Neighbourhood Socioeconomic Context and Self Reported Health and Smoking: A Secondary Analysis of Data on Seven Cities. Journal of Epidemiology and Community Health, 56, 935-942. http://dx.doi.org/10.1136/jech.56.12.935

Robert, S. A. (1998). Community-Level Socioeconomic Status Effects on Adult Health. Journal of Health and Social Behavior, 39, 18-37. http://www.jstor.org/stable/10.2307/2676387 http://dx.doi.org/10.2307/2676387

Room, G. (1995). Poverty and Social Exclusion: The New European Agenda for Policy and Research. In G. Room (Ed.), Beyond the Threshold: The Measurement and Analysis of Social Exclusion (pp. 1-9). Bristol: Policy Press.

Ross, C. E., \& Mirowsky, J. (2001). Neighborhood Disadvantage, Disorder, and Health. Journal of Health and Social Behavior, 42, 258-276. http://www.jstor.org/stable/10.2307/3090214 http://dx.doi.org/10.2307/3090214

Sen, A. K. (2000). Social Exclusion: Concept, Application, and Scrutiny. Manila: Office of Environment and Social Development, Asian Development Bank.

Srinivasan, S., O’Fallon, L. R., \& Dearry, A. (2003). Creating Healthy Communities, Healthy Homes, Healthy People: Initi- 
ating a Research Agenda on the Built Environment and Public Health. American Journal of Public Health, 93, $1446-1450$. http://dx.doi.org/10.2105/AJPH.93.9.1446

Stafford, M., \& Marmot, M. (2003). Neighbourhood Deprivation and Health: Does It Affect Us All Equally? International Journal of Epidemiology, 32, 357-366. http://dx.doi.org/10.1093/ije/dyg084

Tashakkori, A., \& Teddlie, C. (1998). Mixed Methodology: Combining Qualitative and Quantitative Approaches (Vol. 46). Thousand Oaks, CA: Sage Publications.

Thorat, S. (2005). Caste, Social Exclusion and Poverty Linkages-Concept, Measurement and Empirical Evidence. Concept Paper for PACS, New Delhi.

Wilkinson, R. (1996). Unhealthy Societies: The Afflictions of Inequality. London: Routledge. http://dx.doi.org/10.4324/9780203421680

Yen, I. H., \& Kaplan, G. A. (1999). Neighborhood Social Environment and Risk of Death: Multilevel Evidence from the Alameda County Study. American Journal of Epidemiology, 149, 898-907. http://aje.oxfordjournals.org/content/149/10/898.short http://dx.doi.org/10.1093/oxfordjournals.aje.a009733

Yen, I. H., \& Syme, S. L. (1999). The Social Environment and Health: A Discussion of the Epidemiologic Literature. Annual Review of Public Health, 20, 287-308. http://dx.doi.org/10.1146/annurev.publhealth.20.1.287

Zheng, S., Long, F., Fan, C. C., \& Gu, Y. (2009). Urban Villages in China: A 2008 Survey of Migrant Settlements in Beijing. Eurasian Geography and Economics, 50, 425-446. http://dx.doi.org/10.2747/1539-7216.50.4.425

Ziersch, A. M., Baum, F. E., MacDougall, C., \& Putland, C. (2005). Neighbourhood Life and Social Capital: The Implications for Health. Social Science and Medicine, 60, 71-86. http://dx.doi.org/10.1016/j.socscimed.2004.04.027 